dipping purposes, but should prove useful as an ingredient of preventive dusts and maggot dressings.

The presence of dung and urine in the dip may seriously impair its protective action. Suint, the water-soluble fraction of the fleece, is a further contaminant which may be more important. Suint contains a large proportion of soap; this dissolves in the dipping fluid and completely changes its physical properties, the surface tension falling appreciably. When much suint has accumulated in the dip, the retention of arsenic by the fleece is reduced and the immunity to artificial maggot infestation is decreased; these observations may explain the poor results often obtained when large numbers of sheep are dipped without changing the bath.

With regard to the treatment of infested sheep, further information is required about the breeding habits of the fly. If the sheep blow-fly population is derived mainly from live sheep, and not from carrion, then the first essential of a good dressing is the killing of maggots. It should also promote rapid healing and protect the wound against re-infestation.

In a problem of this nature there are two main avenues of attack : the host might be made immune or very resistant, or the pest might be greatly reduced or exterminated. Work in Britain has been con- centrated mainly on chemical means of protecting the host by the use of dips. Jetting has been tried in Scotland, but protective dusts have not been experimented with on a large scale. The control measures at present available to the farmer are dipping and crutching. Indirectly, the prevention of scouring in sheep by good shepherding and the use of anthelminthics, is important.

Our knowledge regarding the ecology of the sheep blowfly in Britain lags very much behind the biochemical work on the maggots and the susceptibility of the host. We know practically nothing about sheep blowfly populations or the ecological factors governing them. Perhaps the most pressing need is for knowledge of carrion-infesting flies, in particular the question of competition. Important practical recommendations resulted from such a study in Australia.

This unsatisfactory position is considered to be due to the facts that: (1) the farmer, not realizing how serious are the losses caused by sheep blowfly, has not pressed for control measures ; $(2)$ the subject is not one normally dealt with by either the veterinary investigation officer or the advisory entomologist; (3) money for this ecological work has not been available ; (4) failure adequately to carry the results of present research over to the farmer.

\title{
THE CAMPBELTOWN RAISED BEACH AND ITS CONTAINED STONE INDUSTRY*
}

\author{
By Dr. W. J. McCallien and A. D. Lacaille
}

$\mathrm{T}$ HE flint implements of Campbeltown are well known. The original discovery was made in the deposits of the so-called 25-ft. raised beach by a local naturalist, Alexander Gray, in 1894. The Abbé $H$. Breuil described and discussed them in his classic paper, "The Pre-Neolithic Industries of Scotland" (Proc. Soc. Ant. Scot., 56, 261-81 ; 1921-22).

As many diverging views have since been expressed on these artefacts, excavations were recently undertaken to determine their stratigraphical situation and cultural age, a site in the post-glacial raised beach, some $35 \mathrm{ft}$. above ordnance datum, near the Albyn Distillery, Campbeltown, being selected for exploration. The work yielded 1,235 objects attesting man's attention. Of these 724 were definable artefacts, 559 being of flint (the raw material imported from Ireland), 157 of quartz and 8 of schistose grit. Many are heat-crackled, a feature commonest among the waste which indicates their derivation from an occupation-site. The conditions of discovery are generally similar to those of previous finds in that the artefacts were found distributed throughout the upper part of the beach deposits, although locally they were concentrated.

The components of the Campbeltown stone industries constitute the earliest evidence of the colonization of this part of Scotland. Originating from sites occupied on the shore during the time of rising sealevel in the early post-glacial period, they were incorporated into the beach formation during the emergence which followed.

-Summary of a paper read to the Society of Antiquaries of Scotland on February 22.
The present study now enables us to determine a closer connexion between the industries of the equivalent raised beach on the Scottish and Irish sides of the North Channel. The Upper Palæolithic tradition so often stressed as being strong in the Argyll beach industry is not the only influence which left a mark on the stone products of the settlers. A faint Azilian strain appears in some steep round scrapers, while Tardenoisian influence is manifested by some artefacts, including that significant cultural index the micro-burin. The infiltration of Baltic Forest Culture is also suggested by a few objects, a small pick being particularly significant. On the other hand, some tool-forms, such as the "Larne pick", previously unknown outside Ireland are now seen to have a place in Scotland.

This new Campbeltown series of implements, belonging to what is essentially a fine blade industry, compares strictly with those of the Antrim beach assignable to the Early Atlantic climatic period and to Early Mesolithic culture. The Campbeltown industry is equated with Movius's Horizon 2 (Early Larnian) at Cushendun (Proc. Roy. Irish Acad., 46, c.r., $1-84 ; 1940)$. The Campbeltown group, however, including gravers, micro-burins, trimmed and obliquely truncated flakes abruptly retouched, and a pick, is more comprehensive and advanced cultur. ally than its close counterpart across the North Channel.

The conclusion is reached that $(a)$ from various pre-Neolithic elements the beach people developed a provincial culture of their own, (b) Tardenoisian methods of implement manufacture had reached 
Scotland earlier than was thought, and (c) the influence of Baltic Forest Culture was more widespread in Scotland, both in geographical distribution and duration in time than has generally been held to be the case.

So far, only the more complex Antrim raised beach provides evidence of the evolution of the lithic element in the pre-Neolithic culture which flourished on the shores of south-western Scotland and northeastern Ireland, but there exist indications to suggest that future inquiries in Scotland will afford analogies.
The Campbeltown Early Mesolithic industry must antedate the advanced bone and antler industries from the Argyll shell-mounds and caves, the situation of which points to occupation during Late Atlantic times following the maximum submergence. This is possibly equatable with the Littorina transgression of the Baltic. In Baltic chronology, which cannot yet be applied with certainty to Scotland, the period of the Littorina raised beach may be taken as 5000-2500 B.c., the maximum transgression in Denmark taking place about 4500 B.c.

\section{EARLY MATERIA MEDICA CABINETS}

A $S$ a quiet and pleasing relief from topics bearing A upon the War, Mr. E. Saville Peck took as the subject of his lecture at the February scientific meeting of the Pharmaceutical Society "Three Early Materia Medica Cabinets in Cambridge".

The collections described, namely, those of J. P. Vigani, John Addenbrooke and William Heberden are of special interest for various reasons, but notably because they mark the time when the atmosphere of indifference to medical teaching which had hitherto prevailed at Cambridge began to be dispelled. Vigani, a native of Verona, who had taught chemistry in Cambridge for twenty years, was invested with the title of professor of chemistry in 1703, and it would seem that a chest containing more than six hundred specimens of materia medica, which was found in 1922 under the staircase of the library of Queens' College, was the one from which he lectured.

Mr. Peck has told, on a previous occasion, of the evidence on which he based his belief, and his description of the contents of the chest, which was published some years ago, forms a useful addition to the literature of drugs.

John Addenbrooke's chest, now in St. Catherine's Library, contains, besides the drugs, many geological specimens which he collected and labelled when in his undergraduate days he used "to range the circumjacent country, Cherryhinton, Grantchester and Trumpington and searched the chalk pits and moors for fossils and simples". The chest itself is made of deal and is much the same in shape as a flat-topped writing desk of the present day, having a frog hole in the middle, drawers all the way down and also at the back of the recess; each drawer is divided by wooden partitions into compartments of about 3 inches square. There are about twenty such drawers containing a fine collection of materia medica. Perhaps the best of these collections are the drawers containing gums, resins and the like, the drawer of roots and rhizomes and another containing barks and woods, and still another filled with seeds. Some of these specimens were labelled by Addenbrooke himself.

Incidentally, there is a fine specimen of coffee berries in Addenbrooke's chest; this "drug" had but recently been introduced, and a few years earlier, in 1680, had been described as being "most useless, since it serves neither for nourishment nor debauchery". Among other drugs introduced in the seventeenth century and specimens of which Addenbrooke collected, were jalap, serpentaria, calumba and balsam of Tolu.

The third chest described by Mr. Peck was that of William Heberden, who was admitted a sizar of St. John's in 1724, and was made a medical fellow in 1734, proceeding to the degree of M.D. in 1739 . $\mathrm{He}$ gave an annual course of lectures in materia medica, and made good use of his knowledge of the classics to adorn them; the collection of materia medica which he had formed to illustrate his lectures he presented to his college when he left Cambridge to practise in London, where among his patients was Dr. Johnson. Boswell relates that when he was asked what physician he had sent for, he replied, "Dr. Heberden, ultimum Romanorum".

Heberden's cabinet is made of oak and contains in the upper portion twenty-eight drawers and below a cupboard with two shelves. The contents are noted in a manuscript catalogue of July 10, 1751. The three cabinets described have many points of similarity; all three contain almost identical substances, most of which are mentioned in Culpeper's Herbal and the London Pharmacopœia of the time. They are contained in little paper trays folded in similar fashion and placed in the various positions in the drawers.

Cambridge is fortunate in possessing such treasures and, as Mr. Peck acknowledged, pharmacists are grateful to the Colleges for the care they have taken of them for more than two centuries.

\section{RECOGNITION OF COLOURED LIGHT SIGNALS}

$\mathrm{A}$ PAPER was read to the Illuminating Engineering Society on February 11 by J. G. Holmes on the recognition of coloured light signals. The apparatus described in the first part of the paper was made to provide a spot of coloured light suitable for observation under conditions comparable with night signalling, and capable of variation through a wide range of colours, the energy distributions of which were similar to those of the usual signalling colours.

The apparatus is similar to the Donaldson colorimeter, but with eleven primaries. Eleven beams of light from a common light source pass through coloured filters and through adjustable apertures, 